1. Caucob P, Axler O, De Zuttere D, et al. Amyloidosis and cardiac involvement. Ann Med Interne (Paris) 2000; 151 (8): 611-7.

2. Berk JL. Pleural effusions in systemic amyloidosis. Curr Opin Pulm Med 2005; 11 (4): 324-8

3. Berk JL, Keane J, Seldin DC, et al. Persistent Pleural Effusions in Primary Systemic Amyloidosis. Etiology and Prognosis. Chest 2003; 124 : 969-977.

4. Ikeda S, Takabayashi Y, Maejima Y, et al. Nodular lung disease with five years survival and unilateral pleural effusion in AL amyloidosis. Amyloid 1999; 6: 292-296.

5. Maeno T, Sando Y, Tsukagoshi M, et al. Pleural amyloidosis in a patient with intractable pleural effusion and multiple myeloma. Respirology 2000; 5: 79-80.

\section{Síndrome antifosfolípido en paciente con bacteriemia por Salmonella enteritidis}

\section{Sr. Director:}

El síndrome antifosfolípido es una enfermedad autoinmune caracterizada por la asociación de anticuerpos antifosfolípido y diversas manifestaciones clínicas secundarias a un síndrome de hipercoagulabilidad. Los anticuerpos antifosfolípido se descubrieron por primera vez en 1906 en pacientes con sífilis (1-5), desde entonces se han recogido asociados a distintas entidades. Entre ellas destacan enfermedades autoinmunes, neoplasias, fármacos e infecciones. Dentro de este último grupo, se han descrito en infecciones víricas, bacterianas y parasitarias. Se asocia habitualmente a patógenos virales, sobre todo virus de la inmunodeficiencia humana, hepatitis $\mathrm{C}$, varicela zóster y citomegalovirus. En las infecciones bacterianas se han recogido casos secundarios a Staphylococcus aureus, estreptococo, sífilis, borrelia, leptospira y Klebsiella (1-4). En la literatura revisada, sólo hemos encontrado dos casos publicados en los cuales la infección por Salmonella typhi se relacionó con el desarrollo de un síndrome catastrófico antifosfolipídico $(6,7)$. Presentamos a continuación un caso de síndrome antifosfolípido en un paciente con bacteriemia por Salmonella enteritidis.

Se trata de una mujer de 43 años, con alergia a penicilina e hipertensión arterial. Diagnosticada de síndrome de Tolosa Hunt (oftalmoplejía dolorosa asociada a granulomatosis idiopática del seno cavernoso), seguía revisiones periódicas en consulta de neurologia. En una analítica de control realizada un año antes del ingreso actual de detectaron niveles de anticuerpo anticardiolipina de 31 UPL (valores normales < 20 UPL). La paciente se encontraba en ese momento asintomática y todos los controles de dicho anticuerpo solicitados posteriormente fueron negativos. Recibía tratamiento con corticoides desde hacía diez años, ante el mal control de los síntomas se añadió azatioprina dos meses antes del ingreso. Habitualmente, seguía tratamiento con alendronato sódico, calcio, ranitidina, torasemida e indometacina.

Consultó por un cuadro de cuatro días de evolución de febrícula y tiritona. No refería clínica neurológica, respiratoria, gastrointestinal, genitourinaria, lesiones cutáneas ni alteraciones articulares. Posteriormente, aparecieron nódulos subcutáneos en ambos antebrazos.

En la exploración física se objetivó $\mathrm{T}^{\mathrm{a}}$ de $37,5^{\circ} \mathrm{C}$ y hábito cushingoide sin otros hallazgos significativos. El hemograma mostró leucocitos 2.700 miles/ $\mu \mathrm{L}$ (segmentados 82,7\%), Hb $10 \mathrm{~g} / \mathrm{dl}$, Hto $30 \%$, VCM 99 fl, plaquetas 24.000 miles/ $\mu \mathrm{L}$, en el estudio de coagulación destaca fibrinógeno $1050 \mathrm{mg} / \mathrm{dl}$, y la bioquímica fue normal. En el análisis elemental de orina proteínas ++ , hematíes +++ , leucocitos ++ , sedimento 30-35 leucocitos/campo, 15-20 hematíes/campo, bacteriuria intensa, cilindros granulomatosos. El proteinograma proteínas totales $4,8 \mathrm{~g} / \mathrm{dl}$, albúmina $1,82 \mathrm{~g} / \mathrm{dl}$, $\alpha 10,64 \mathrm{~g} / \mathrm{dl}, \alpha 2$ 1,23 g/dl, inmunoglobulinas $\mathrm{G} 614 \mathrm{mg} / \mathrm{dl}$, proteina $\mathrm{C}$ reactiva $8,58 \mathrm{mg} / \mathrm{dl}$, factor reumatoide $20 \mathrm{UI} / \mathrm{ml}$. El urocultivo fue negativo. Se realizó punción-aspiración de los nódulos subcutáneos, en el cultivo de dicho material y en los hemocultivos se identificó salmonella enteritidis serogrupo $\mathrm{C}$.

Durante el ingreso, la paciente debutó de forma súbita con disnea intensa, se realizó electrocardiograma donde se objetivó taquicardia sinusal, bloqueo de rama derecha y aparición de S1Q3T3. Se realizó tomografía axial computerizada torácica informada como tromboembolismo masivo bilateral con zonas de infarto pulmonar, en el eco-doppler de miembros inferiores se objetivó trombosis venosa profunda aguda con un trombo flotante en la femoral común y otro no adherido a lo largo de toda la vena femoral superficial y poplitea. La paciente precisó ingreso en la unidad de cuidados intensivos ante la aparición de shock obstructivo. Se solicitó estudio de trombofilia donde se detectaron niveles de anticuerpos anticardiolipina de 83 UPL. Las determinaciones de anticoagulante lúpico, proteínas $\mathrm{C}$ y $\mathrm{S}$, antitrombina III, mutación del gen de la protrombina, homocisteina y factor $\mathrm{V}$ de Leyden se encontraban dentro de la normalidad. Las fracciones de complemento presentaban niveles normales y los ANA, anti DNA y ANCA fueron negativos.

Se colocó un de filtro de vena cava inferior e inició tratamiento con enoxaparina y acenocumarol. La paciente ha evolucionado favorablemente, encontrándose asintomática y con hemograma normal en los controles posteriores en consulta. Los niveles de anticuerpos anticardiolipina se han negativizado tras tres meses de tratamiento.

Los anticuerpos antifosfolípido son una familia heterogénea de inmunoglobulinas. Interaccionan con complejos fosfolipídicos y proteínas plasmáticas que actúan como cofactores, provocando fenómenos trombóticos a distintos niveles. Los más frecuentes son los anticuerpos anticardiolipina y el anticoagulante lúpico. Interactúan con dianas antigénicas, entre ellas se encuentran la beta 2- glicoproteína I (beta2GPI), la protrombina y la anexina V.

El origen de estos anticuerpos no está claro. Se sugiere la existencia de dos tipos, unos de etiología infecciosa y otros trombogénicos, aunque esta separación actualmente no está bien delimitada. Algunos autores han demostrado la relación entre ciertos epítopos de origen infeccioso y la beta2GPI. Esta glicoproteína plasmática es un inhibidor de la coagulación y de la agregación plaquetaria. La producción de anticuerpos contra ella, debidos a la similitud con un agente infeccioso, puede desencadenar la aparición de fenómenos trombóticos en pacientes predispuestos genéticamente $(8,9)$.

Las manifestaciones clínicas son muy diversas. La presentación más frecuente es la trombosis venosa profunda de miembros inferiores, aproximadamente la mitad de los pacientes cursan con tromboembolismo pulmonar (5). También son habituales la afectación neurológica, las pérdidas fetales y la trombocitopenia. Cuando la oclusión microvascular afecta a tres ó más órganos se habla de síndrome antifosfolipídico catastrófico.

En los artículos revisados que recogen la coincidencia entre infección por Salmonella typhi y síndrome antifosfolípido $(6,7)$, se sugiere que los lipopolisacáridos de esta bacteria podrían actuar como desencadenantes del cuadro mediante la teoría del mimetismo.

En nuestro caso, se disponía de una determinación previa elevada de anticuerpos anticardiolipina. Por este motivo, aunque probablemente la infección por Salmonella enteritidis actuó como desencadenante del cuadro, no se puede descartar que el mismo se hubiera producido espontáneamente.

El tratamiento de elección es la anticoagulación oral. La duración del mismo no está clara, ya que en algunas series se ha evi- 
denciado un riesgo de recurrencia del 50-78\% tras suspenderla. Por este motivo, algunos autores recomiendan su mantenimiento a largo plazo $(5,10)$. Tanto en nuestro caso, como en los anteriormente citados, los niveles de anticuerpos se normalizaron tras iniciar el tratamiento anticoagulante. En algunos casos, se sugiere la utilización de antibióticos de forma coadyuvante ya que uno de los posibles desencadenantes son los agentes infecciosos (8).

\section{D. Mañas, P. Calderón, J. Yanes, B. Ballester, J. Gijón}

\section{Servicio de Medicina Interna. Complejo Hospitalario. Ciudad} Real

1. Asherson RA, Cervera R. Antiphospholipid antibodies and infections. Ann Rheum Dis 2003; 62: 388-393.

2. Uthman IW, Gharavi AE. Viral infections and antiphospholipid antibodies. Semin Arthritis Rheum 2002; 31: 256-263.

3. Dalekos GN, Zachou K, Liaskos C. The antiphospholipid syndrome and infection. Curr Rheumatol Rep 2001; 3; 277-285.

4. Orts JA, Zúñiga A, Orera M. Actualización del síndrome antifosfolipidico. Med Clin (Barc) 2003; 121: 459-471.

5. Levine JS, Branch DW, Rauch J. The antiphospholipid syndrome. N Engl J Med 2002; 346: 752-763

6. Hayem G, Kassis N, Nicaise P, Bouvet P, Andremont A, Labarre C, et al. Systemic lupus erythematosus associated with catastrophic antiphospholipid syndrome occurring after typhoid fever. A possible role of salmonella lipopolisaccharide in the occurrence of diffuse vasculopathy-coagulopathy. Arthritis Rheum 1999; 42: 1056-1061.

7. Uthman I, Taher A, Khalil I, Bizriu AR, Gharavi AE. Catastrophic antiphospholipid syndrome associated with typhoid fever: comment on the article by Hayem, et al. Arthritis Rheum 2002; 46: 850.

8. Blank M, Shoenfeld Y. Beta-2-glycoprotein-I, infections, antiphospholipid syndrome and therapeutic considerations. Clin Inmunol 2004; 112: 190-199.

9. Blank M, Krause I, Fridkin M, Nathan K, Kopolovic J, Iris Goldberg, et al. Bacterial induction of autoantibodies to -2-glicoprotein-I accounts for the infectious etiology of antiphospholipid syndrome. J Clin Invest 2002; 109: 797-804.

10. Godeau B, Piette JC. The significance and treatment of antiphospholipid antibodies. Press Med 2004; 33: 944-952.

\section{Miositis viral aguda del adulto}

\section{Sr. Director:}

La miositis aguda viral del adulto es una rara entidad. Consiste en un cuadro brusco caracterizado por un intenso dolor, inflamación e incapacidad funcional, de predominio en MMII. Suele ir precedido días antes de una infección de vías respiratorias, algias difusas, malestar y generalmente fiebre (compatible con cuadro viral). Habitualmente mejora rápidamente en pocos días, con reposo y tratamiento sintomático.

Describimos el caso de un paciente varón de 38 años, deportista, ejecutivo sin enfermedades de interés ni tratamiento habitual, que acude a urgencias referido por su médico de empresa por dolor, inflamación y tumefacción de la región gemelar bilateral que le incapacita la marcha normal, forzándole a caminar "de puntillas", junto con fiebre alta $\left(38,5^{\circ} \mathrm{C}\right)$. Refiere tres días antes un cuadro compatible con infección de vías respiratorias altas de características virales. Tiene dos hijos pequeños que también habían presentado los mismos síntomas respiratorios.

Se le realizan las siguientes pruebas: hemograma con 15.980 leucocitos/ml (74,5\% N, 16\% L, 5\% M), Hb 15 g/dl y 200.000 plaquetas/ml. Bioquímica : CPK 554 U/l que se normalizó con enzimas hepáticas y de colestasis normales, PCR 2,1 mg/dl, ASLO 180 $\mathrm{UI} / \mathrm{ml}$ y hormonas tiroideas, iones, lipidograma y proteinograma dentro de la normalidad. Orina: normal. EKG: sin alteraciones. Rx tórax: sin hallazgos significativos. Inmunología: ANAs negativos, factor reumatoide negativo, inmunoglobulinas en rangos normales. C3: $184 \mathrm{mg} / \mathrm{dl}(\mathrm{N}<120)$ y C4 normal. Eco doppler venoso bilateral: descarta TVP. Serología: Micoplasma, Legionella, Borrelia burgdorferi, VRS, Ricketsia, adenovirus, toxoplasma, Coxackie B1 y B4, EBV, Influenza A y B, VIH, VHA, VHC negativos. CMV Ig $\mathrm{G}$ positivo con CMV Ig M negativo.

Tras unos días de reposo, hidratación y antiinflamatorios no esteroideos se resuelve ad integrum.

El informe de la serología viral no muestra resultados significativos, aunque dados los antecedentes, la clínica y posteriormente la evolución favorable en un hombre por lo demás sano, podría relacionarse el cuadro con una infección viral.

La miositis aguda es un proceso que habitualmente afecta a niños (1), siendo por consiguiente bastante citado en el ámbito pediátrico (2); y cuando lo hace a otras edades, suele ser tras infección por influenza (3), sobre todo en personas mayores, infectados por VIH o, incluso, y mucho más raramente, por el bacilo tuberculoso (4) o por enfermedades autoinmunes, como la enfermedad de Crohn (5). Es excepcional que se produzca, como en nuestro caso, en la edad media de la vida y sin comorbilidades asociadas.

Habitualmente es un cuadro que produce un intenso dolor sin historia de traumatismo o antecedentes familiares de miopatías, y que, en tanto se resuelve, supone para el enfermo un auténtico impedimento para la deambulación. El tono, la fuerza, la sensibilidad y los reflejos suelen estar inalterados o estarlo mínimamente.

El estado general suele ser bueno, aunque en ocasiones se asocie fiebre y se ha descrito, aunque excepcionalmente, mioglobinuria.

A pesar de la notable benignidad de la miositis, conviene estar atentos a la posible aparición de complicaciones potencialmente más peligrosas, como una rabdomiolisis, fracaso renal agudo por mioglobinuria severa o el desarrollo de trombosis a nivel de un miembro inflamado y poco movilizado, sobre todo en enfermos de edad avanzada y con comorbilidad importante asociada.

Es deseable completar el estudio identificando la etiología probable con determinaciones serológicas, aunque es frecuente que, a pesar de todas las pruebas complementarias el diagnóstico quede sin aclarar (2). No obstante, debido a la benignidad del cuadro, es raro que se realicen pruebas invasivas como la biopsia muscular para conocer la etiología cuando la evolución es satisfactoria.

\section{J. Núñez Gil, E. Álvarez-Rodríguez, M. J. Amérigo García, A. Braña Cardeñosa, L. Díaz Vidal, R. García Cobos}

\section{Servicio de Medicina Interna I. Hospital Clínico San Carlos. Madrid}

1. Lundberg A. Myalgia cruris epidemica. Acta Pediatr 1957; 46: 18-31.

2. García R, Campuzano S. Miositis aguda en relación con el virus de la gripe. Rev Pediatr Aten Primaria 2003; 5: 577-581.

3. Yoshino M, Suzuki S, Adachi K, Fukayama M, Inamatsu T. High incidence of acute myositis with type A influenza virus infection in the elderly. Intern Med 2000; 39: 431-2.

4. Wang JY, Lee LN, Hsueh PR, Shih JY, Chang YL, Yang PC, et al. Tuberculous myositis: a rare but existing clinical entity. Rheumatology 2003; 42: 836-40.

5. Christopoulos C, Savva S, Pylarinoud S, Diakakis A, Papavassiliou E, Economopoulos P. Localised gastrocnemius myositis in Crohn's disease. Clin Rheumatol 2003; 22: 143-5. 